\title{
Breeding Soundness Inspection and Production Features of Bullocks under Ecological Conditions in Free State Region, South Africa
}

\author{
T. Netshilema, G. Zuma-Netshiukhwi, and N. B. Nongovhela
}

\section{ABSTRACT}

\begin{abstract}
Assessing the fertility of bullocks preceding to use as breeding animals make apparent economic if it were possible. Fertility is not possible predicted by means of a breeding soundness evaluation (BSE), but by the application of minimum standards to a set of accepted procedures, which supports informed decision makers to the breeding potential of the bullock. An bullocks found to satisfy these criteria in Central Performance Testing (CPT) known as Phase $\mathrm{C}$, is reckoned to be breeding sound (BS). Furthermore, breeding success depends on the reproductive performance of both the cow and the bull. Breeding bull is likely to service a large number of heifers or cows in planned breeding season. The efficiency of a bullock can be based on the average daily gain (ADG) and feed conversion ratio (FCR) but poor breeding sound evaluation can be regarded as infertile. Bull breeding soundness evaluations (BSEs) are significant economic management of beef herd management and depends on adequate semen quality, physical soundness and serving capacity. Furthermore, assessment of scrotal circumference (SC), libido, testicular measurement and semen parameters often not done during a routine breeding soundness examination. The aim of this study was to depict using BSE whether bullocks would be fertile under Phase $\mathrm{C}$. The relationship of BSE and production characteristics in central performance testing is challenging to identify fertility in bullocks within 112 given days of CPT. This study investigated performance data extracted from Integrated Registration and Genetic Information System (Intergis) managed by Agricultural Research Council Glen Bull Testing Centre. There were three breeds investigated, namely, Simmentaler, Santa Gertrudis and Limousin for the period of 2007 to 2017, were analysed to determine the dominance and importance of factors affecting breeding soundness classification.
\end{abstract}

Keywords: bullocks, breeding soundness, environmental conditions. Reproductive performance.

\section{INTRODUCTION}

High fertility level in any breeding animal within the herd is a key component of efficient calf producing. A deficiency in breeding capability of one bull has a huge impact on herd productivity, since individual bull service numerous females [1]-[4]. There are substantial differences in fertility among particular bulls [5]. Previous studies indicate, maximum fertility was similar for herds versus males. However, since minimum fertility was less for the males, it revealed that beef bulls contribute significantly to fertility failures, as bulls with reduced fertility are regularly used to service many females [2], [6], [7], [35].

The two universal methods of assessing the breeding soundness potential of bulls are either breeding a large number of normal [8], [9], fertile females and determining pregnancy and /or calving rates [10]-[12] or conducting a breeding soundness evaluation. A breeding trial is the ultimate fertility test, but expensive if reproductive performance is poor. Thus, conducting breeding soundness
Submitted : October 05, 2021

Published : January 19, 2022

ISSN: $2684-1827$

DOI: $10.24018 /$ ejfood.2022.4.1.391

\section{T. Netshilema}

Agricultural Research Council, Animal Production Institute, Beef Cattle Improvement, Irene, South Africa.

(e-mail: NetshilemaT@arc.agric.za) G. Zuma-Netshiukhwi *

Agricultural Research Council, Natural Resources and Engineering, Glen College of Agriculture, Bloemfontein, South Africa.

(e-mail: ZumaNetshiukhwiG@ ${ }^{@}$ arc.agric.za) N. B. Nongovhela

Tshwane University of Technology, Faculty of Science, Department of Animal Science, Pretoria, South Africa.

(e-mail: NkhanedzeniN@dalrrd.gov.za)

*Corresponding G. Zuma-Netshiukhwi evaluation [13]-[15] prior breeding season is highly recommended [16]. Such inspections identify bullocks with extensive deficits in fertility, but subfertile bullocks unidentified [6].

Bullock breeding soundness evaluations (BSEs) play a crucial economic element of beef management [17]-[19], [7], [16] and are conducted to determine a bullocks capability to breed calves under natural mating management [16], [12] Precise conduct and reporting of BSE supports bull buyers, owners, and managers to make appropriate bull selection and management decisions [8], [20]-[26]. Sub-fertility of bulls is a major issue in in the cattle production sector in Africa and elsewhere [27]. Previous studies detailed that about 50\% of bulls fail a BSE in the 3 months post-sale, whereas veterinary practitioners in the Free State region report that approximately $20 \%$ of bulls fail a routine BSE.

Previous studies, emphasize the significance of proper bullock selection as a rapid way to make genetic improvement to the cattle herd [23]-[28]. Structural soundness, environmental conditions and health should be evaluated along with performance data and Expected Progeny 
Differences. BSEs information are beneficial in marketing bulls. On-farm BSE data, combined with breed association record programs, provide prospective buyers with good indications of underlying genetic merit for traits measured [28], [29]. Livestock enterprise in South Africa, contributing about 20-30\% [29], [30] of the total agricultural output per annum [31].According to [32], [33] fertility traits are lowly heritable, and farmers look for traits that are easy to measure such as scrotal circumference and has indicated relationship with fertility. According to [34] breeding programs are tailored to be efficient rather than general preference of an individual breeder. Bulls are evaluated using many criteria and vary depending on the purchaser's goals such as breed preference and soundness.

Adaptability of cattle refers to the genetic and physiological changes, which occurs in animal response to internal and external stimuli [35], [36]. Physiological adaptation is the capacity and the process of adjustment on an animal to itself, and to external physical environment [35]. Other significant factor is the genetic adaptation, which is the heritable characteristics for survival of a population in a particular ecology. Animals raised under extensive grazing conditions are imposed to variety environmental challenges compared to pen-fed animals. Climate studies have indicated that the arid and semi-arid areas are possible to experience an intensification in the severity and length of droughts as well as in increased temperatures. Therefore, it is recommended that under extreme weather conditions locally adapted breeds will have a competitive advantage over the exotic breeds [39]-[41] [37]. Temperature is one of the most crucial climatic parameters in cattle production as it determines the breeds adaptable to a particular region.

The animal body temperature variation exhibits the degree in which an animal can counterattack adverse environmental conditions and the health status of an animal. Though cattle are known to be homothermous, since body temperature remains fairly constant despite external environmental temperature changes [34], [38]. The average body temperature of cattle is $39.0^{\circ} \mathrm{C}$ with a minimum of $37.0^{\circ} \mathrm{C}$ and maximum of $41.0^{\circ} \mathrm{C}$. According to [19], [39]-[41] any substantial deviation from standard maximum represents signs of poor inadaptability and/or poor health status, become hyperthemic with low growth rates and infertility. Previous studies have indicated that bull productiveness and semen quality is affected by management factors based on body conditions, environmental stresses and photoperiod [42]. Such factors relate to body condition [14], [43], [44], testicle size, abnormal scrotal thermoregulation [7], [45], [46], age, stress [47] and season. This study determined the occurrence and the importance of adaptability, soundness evaluation and classification of bullocks in Glen Bull Testing Centre.

\section{DATA AND METHODS}

\section{A. Review Stage}

The Glen Bull Testing Centre is located in the south-west Free State province, in Motheo district of South Africa. The province is located between the latitudes $26.6^{\circ} \mathrm{S}$ and $30.7^{\circ} \mathrm{S}$ of the equator and $24.3^{\circ} \mathrm{E}$ and $29.8^{\circ} \mathrm{E}$ of the Greenwich meridian. The regional topography in the north-eastern and eastern parts of the Free State province is multifaceted, with low altitudes of $1.800 \mathrm{~m}$, situated at an elevation of $1,395 \mathrm{~m}$ above sea level. The long-term climatic data indicate that the area has monthly mean sunshine hours of about 319.5, 296.5 and 296.3 in November, December, and January, respectively. The annual sunshine hours and annual average rainfall of about 3312.3 and $559 \mathrm{~mm}$ respectively in the area. The region gets the lowest July rainfall and the highest January rainfall with the coldest months being June to August the minimum temperatures can drop to below $-10^{\circ} \mathrm{C}$.

\section{B. Glen Area Soil Types}

In the Free State, the factors, which have played a dominant role in soil formation, are parental material and climate. Glen is a farm of approximately 4600 ha in size; divided into various land-use practices, for crop production, animal production, natural veld, and cultivated pastures. The farm has multiple soil types suitable for the land use practices. On the pasture camps are four classified soil types which are: Bonheim, Swartland, Glenrosa, Valsrivier and Hutton form to mention a few.

\section{Experimental Site and Breeds}

Breeding soundness evaluation of 300 bullocks of three different breeds from 2007 through 2017, were obtained from all over the Free State province. The selected bullock breeds were Simmentaler (SIM), Santa Gertrudis (SGT) and Limousin (LIM). A total of 100 each beef breeds were evaluated for performance at Glen Bull Testing Centre. The selected bullocks had passed the weaning phase. Bullocks were selected for the test according to each breeder's own criteria and there were no minimum requirements of preweaning performance for bullocks entering the performance test. Breeders were encouraged to nominate only bullocks qualifying for entry in a national beef cattle performancetesting scheme.

A vast majority of bullocks were submitted for routine presale or pre-breeding evaluation. An adaptation period of 112 days was provided prior breeding soundness examination. The scrotal circumference was the only trait used to measure breeding sound evaluation due to lack of traits already collected at Central Performance Testing Phase C. Upon bullock's coming, all the animals were initially controlled in a veterinary crush for detailed physical examination and abnormalities. Data points included the following, breeding soundness evaluation and production characteristics, which are adaptation ability, start test, and end weights, feed conversion ratio, average daily g [1]-[4] and body measurements as specified in central performance test (Phase C). Data included year and month of evaluation; age in years; breed; body condition score; physical abnormalities of the feet, legs, and reproductive tract; scrotal circumference measurement. The scrotal circumference was ranked as average, above average, below average, or below the minimum recommended for the breed; semen quality traits; a classification of satisfactory, questionable, or unsatisfactory for semen quality; and for breeding soundness [14], [41]. 


\section{Testing Procedure}

\section{A. Adaptation}

Bullocks ranging at the age of 151 to 250 days were placed in isolation for adaptation purposes for a maximum of 112 days and each breed's minimum and maximum weight at arrival was recorded. The adaptation period was segmented into two phase a 28 day and 84-day period of adaptation and test days respectively. The bullocks were kept on paddocks which accommodate 10 bullocks with each Callan gate with individual feed intake (Table I) equipped designed for groups of 10 animals. A number of bullocks that failed to adapt due to environmental or physiological conditions were returned to the owner.

TABLE I: BULlOCK ADAPTATION FEED PROGRAM FOLLOWED FOR 112 DAYS OF ADAPTATION PERIOD. THE ARRANGEMENT

\begin{tabular}{cc}
\hline Number of weeks & Diet \\
\hline First week & $3 \mathrm{~kg}$ meal diet Hay ad lib \\
Second wee & $6 \mathrm{~kg}$ meal diet 2kg Hay \\
Third week & Meal diet ad lib 1kg Hay \\
Fourth week & Meal diet ad lib 1kg Hay \\
\hline
\end{tabular}

\section{B. Veterinary Measures}

Veterinary safety measures such as immunisation of selected diseases was the prime requirement. Bullocks, which had compliance immunisation certificate, were allowed to the testing facility. Based on the immunisation requirement bullocks had to be immunized against anthrax, botulism, black quarter, and lumpy skin disease and bovine rhinotracheitis (IBR) two weeks prior to arrival at the Phase $\mathrm{C}$ centre. Immunisation against gall-sickness, red water, and heart water, although not compulsory, is recommended. Animals were free of internal and external parasites as well as ringworm, mange, warts, and foot rot. All calves were dosed and immunized against virus scours and para-influenza on arrival at the testing centre. Moreover, the dipping, dosing and inoculation program was adhered to as it is a custom of Glen Bull testing centre.

\section{Bullocks Traits Studied}

Bullocks were weighed on different intervals, namely upon arrival, on weekly basis, and the measurable traits such as Feed Conservation Ratio (FCR), Average Daily Gain (ADG) and Reduced Feed Intake (RFI). Bullocks received $3 \mathrm{~kg}$ of feed during the first week and $6 \mathrm{~kg}$ during the second week thereafter ad lib for the remaining 14 days of the adaptation period. A standardised ration ad lib during the 84-day test period was administered. Individual feed intake and weight gain were recorded on a weekly basis. Interim calculation of intakes and weight gain were done every two weeks. Data capture and verification was conducted on weekly basis in accordance with the requirements and format required by the INTERGIS. Bullocks were weighed on two consecutive days on full stomach. The parameters monitored during the study period were as follows, Feed Conversation Ration, Average Daily Gain, Body Measurements, Scrotal Circumference and Real Ultrasound Scanning.

\section{Feed Conversion Ratio}

Feed conversion ratio is a ratio measuring of the efficiency with which the bullock bodies convert animal feed into the desired output. FCR is the mass of the input divided by the output, the output being the mass of feed per mass of meat. The importance of FCR is based on guiding the breeder on the amount of feed required in the growth cycle of animals, in order to maximize informed decisions and business profitability.

\section{$F C R=$ Total amount of feed consumed/ Weight gain by the animal}

Bullocks, which demonstrate lower FCR, were deliberated as the most efficient consumers of feed. This technique works to determine how efficient the feeding strategy is.

\section{E. Average Daily Gain}

The average daily gain (ADG) was measured after each weighing took place, and the increasing ADG was calculated in order to keep track the bull's performance over the entire test phase and was conducted on weekly basis at a specified regular time. Thus, provided steady indication of the bullock's overall growth performance capability. ADG was calculated by taking the amount of weight bullock has gained since the last weight and dividing the weight by the number of days since that last weight.

$$
A D G=\frac{\text { Final Live Weight }- \text { Initial Live Weight }}{\text { Test days }} \times 100
$$

where ADG = Average daily gain (g/day);

Final Live Weight $=$ Weight obtained at the end of the performance test period $(\mathrm{kg})$;

Initial Live Weight $=$ Weight obtained at the start of the performance test period $(\mathrm{kg})$;

Test days $=$ Total number of days it took to complete the performance test period (d).

\section{F. Body Measurement}

During the end of the test, the Shoulder/hip height and the Length and skin thickness of the bullock were measured by measuring stick. The body measurement allows determines the proportionality and maturity, but it is also in relation to other characteristics, such as live weight. Judging frame size, that is body measurement compared to the average bullock measurement of the same breeds, sex and age; moreover, body measurements serve as important selective considerations.

\section{G. Scrotum Circumference}

The scrotal circumference has a lot of impact on the reproductive performance of cows, since the bull with the bigger SC can be considered the better bull. SC was measured on bullocks and adjusted to 365 days for use in genetic variation. Scrotal circumference is positively correlated with puberty and fertility in young females within the herd. The SC was measured at the end of the adaptation period of 112 days using a standard of $60 \mathrm{~cm}$, scrotal measuring tape. Bullocks were measured while they were restrained with the veterinary crush. Breed inspector for abnormalities and defects also visually assessed the scrotum of each bull. 


\section{H. Real Ultrasound Scanning}

The following respective trait (RTU) were measured during the 84 days of the test by Aqulavet machine: rump fat, rib fat, eye muscle and intra-muscular fat.

\section{Statistical Analysis}

Minitab 17 statistical package is the leading statistical software used for quality improvement and education worldwide which offers a comprehensive set of statistical tools to analyze and explore data. It was selected for its capability to analyse animal data for informed decision making. Data was analysed by Analysis of Variance (ANOVA) through using MiniTab 17, wherein the General Linear Model and the means were separated using the Fishers Least Significance Difference (LSD) test. The Pearson Correlation test was computed to assess the relationship between the studied parameters.

\section{RESUlts AND Discussions}

Breeding soundness evaluations were conducted during all months, however, $90 \%$ of them were during June, July August and September in the Free State region. The number of bullocks evaluated for this study were $\mathrm{N}=300$ for three different breeds. The growth performance of the different bullock breeds during adaptation in Phase $\mathrm{C}$ test period from 2007 to 2017 are presented in Table I, II, II and IV. A significant effect on three different breed weight gain was observed (Table I).

The start weight of the bullocks during adaptation period was significantly different between the breeds $(\mathrm{P}<0.05)$, but all breeds gained weight progressively throughout the adaptation period. The LIM $(271.67 \mathrm{~kg})$ and SIM $(267.58 \mathrm{~kg})$ significantly $(\mathrm{P}>0.05)$ had higher adaptation start weight compared to SGT $(248 \mathrm{~kg})$. The adaptation end weight was significantly different $(\mathrm{P}<0.05)$ across the three breeds, with the LIM significantly $(\mathrm{P}<0.05)$ heavier with $308 \mathrm{~kg}$, followed by the SIM with $294.03 \mathrm{~kg}$ and lastly SGT with $278.20 \mathrm{~kg}$. The weight gain of the bullocks during the adaptation period was significantly different among three the breeds $(\mathrm{P}<0.05)$. The LIM gained significantly $(\mathrm{P}<0.05)$ more weight $(36 \mathrm{~kg})$ compared to both SGT $(29.78 \mathrm{~kg})$ and SIM $(26.46 \mathrm{~kg})$. The adaptation phase ADG across the breeds was also significantly different $(\mathrm{P}<0.05)$.

During the Test Phase $C$, the final end weight of the three breeds was significantly different $(\mathrm{P}<0.05)$, with the SIM weighing $456.40 \mathrm{~kg}$, followed by the LIM with $448.50 \mathrm{~kg}$ and lastly the SGT with $416.22 \mathrm{~kg}$. Above that, the daily gain weight was affected by initial body weight and high initial body weight groups had a higher daily gain than medium and low body weight groups across the breeds.

The body measurements and RTU scans of different beef bullocks breeds during Phase C from 2007 - 2017 are presented in Table II and Table III. The body measurements and RTU scans during the Phase $\mathrm{C}$ test period were significantly influenced by the breed $(\mathrm{P}<0.05)$. The shoulder/hip height, body Length and scrotum circumference of the Simmentaler were significantly higher $(\mathrm{P}<0.05)$ followed by LIM (1234.34, 1366.72 and 335.11, respectively) and lastly by SGT (1250.93, 1433.40 and 348.89 , respectively). The rump fat and rib fat measurement for the Santa SGT were significantly high $(\mathrm{P}<0.05)$ than those other breeds. The EMA of LIM was higher $(\mathrm{P}<0.05)$ than that of SIM (68.45) and SGT. (63.78). The IMF of LIM was significantly different (30.132) to those of the SGT (25.865) and SIM (25.662).

TABLE II: EFFECT OF BREED ON DIFFERENT WEIGHTS

\begin{tabular}{|c|c|c|c|}
\hline & Limousin & $\begin{array}{c}\text { Santa } \\
\text { Gertrudis }\end{array}$ & Simmentaler \\
\hline \multicolumn{4}{|c|}{ Adaptation phase } \\
\hline Start weight & $271.67^{\mathrm{a}} \pm 2.17$ & $248.41^{\mathrm{b}} \pm 1.96$ & $267.58^{\mathrm{a}} \pm 1.48$ \\
\hline End weight & $308.04^{\mathrm{a}} \pm 2.40$ & $278.20^{\mathrm{c}} \pm 2.12$ & $294.03^{b} \pm 1.64$ \\
\hline Weight gain & $36.37^{\mathrm{a}} \pm 1.17$ & $29.78^{b} \pm 1.03$ & $26.46^{\mathrm{c}} \pm 0.80$ \\
\hline Average Daily & $1.30^{\mathrm{a}} \pm 0.04$ & $1.06^{\mathrm{b}} \pm 0.04$ & $0.95^{\mathrm{c}} \pm 0.03$ \\
\hline \multicolumn{4}{|c|}{ Test phase } \\
\hline Final end weight & $448.50^{\mathrm{b}} \pm 3.04$ & $416.22^{\mathrm{c}} \pm 2.69$ & $456.40^{\mathrm{a}} \pm 2.08$ \\
\hline Weight gain & $140.47^{\mathrm{b}} \pm 1.69$ & $138.02^{\mathrm{b}} \pm 1.50$ & $162.37^{\mathrm{a}} \pm 1.16$ \\
\hline $\begin{array}{l}\text { Average Daily } \\
\text { Gain }\end{array}$ & $1.67^{b} \pm 0.02$ & $1.64^{\mathrm{b}} \pm 0.02$ & $1.93^{\mathrm{a}} \pm 0.01$ \\
\hline $\begin{array}{c}\text { Feed conversion } \\
\text { Ration }\end{array}$ & 6.18 & 5.72 & 6.13 \\
\hline
\end{tabular}

TABLE III: BODY MEASUREMENTS AND RTU SCANS OF DIFFERENT BEEF BULLOCKS BREEDS DURING PHASE C $(\mathrm{MEAN} \pm \mathrm{SE})$

\begin{tabular}{|c|c|c|c|}
\hline Parameters & LIM & SGT & SIM \\
\hline $\mathrm{S} / \mathrm{HH}$ & $1234.34^{\mathrm{b}} \pm 465$ & $1277.23^{\mathrm{c}} \pm 411$ & $1250.93^{\mathrm{a}} \pm 3.11$ \\
\hline BL & $1366.72^{b} \pm 5.30$ & $1362.86^{b} \pm 4.69$ & $1433.40^{\mathrm{a}} \pm 3.62$ \\
\hline $\mathrm{SC}$ & $335.11^{\mathrm{b}} \pm 2.09$ & $320.46^{c} \pm 1.85$ & $348.89^{\mathrm{a}} \pm 1.43$ \\
\hline ST & $14.159^{\mathrm{a}} \pm 0.17$ & 14. $21^{\mathrm{a}} \pm 0.146$ & $13.90^{\mathrm{a}} \pm 0.11$ \\
\hline RUF & $43.86^{\mathrm{b}} \pm 1.24$ & $55.98^{\mathrm{a}} \pm 1.10$ & $44.44^{b} \pm 0.85$ \\
\hline RIF & $27.37^{\mathrm{b}} \pm 0.78$ & $32.54^{\mathrm{a}} \pm 0.69$ & $27.66^{\mathrm{b}} \pm 0.54$ \\
\hline EMA & $74.19^{b} \pm 0.62$ & $63.78^{c} \pm 0.55$ & $68.45^{b} \pm 0.42$ \\
\hline IMF & $30.13^{a} \pm 0.78$ & $25.87^{b} \pm 0.69$ & $25.66^{b} \pm 0.53$ \\
\hline
\end{tabular}

$\overline{\mathrm{a}, \mathrm{b}, \mathrm{c}}$ Row means with different superscripts differs significantly $(\mathrm{P}<0.05)$.

SIM: Simmentaler; LIM: Limousin; SGT: Santa Gertrudis; LIM: Limousin; S/HH Shoulder/ Hip height; BL: Body length; SC: Scrotum circumference; ST: Skin thickness; RUF: Rump fat; RIF: Rib fat; EMA: Eye Muscle; IMF: Intra Muscular Fat (Table IV).

Pearson positive correlations coefficients among production characteristics and breed sound evaluation (Scrotum Circumference) traits $(p<0.05)$. Adaptation start have a positive significant relationship with Scrotum Circumference $(r=0.88 ; p<0.05)$; Adaptation weight have positive significant relationship with Scrotum Circumference $(r=0.88 ; p<0.05)$; Test end date have positive significant relationship with Scrotum Circumference $(r=0.52 ; p<0.05)$; Test weight Gain have positive significant relationship with Scrotum Circumference ( $r=0.34 ; p<0.05)$; Shoulder/ hip height have positive significant relationship with Scrotum Circumference $\quad(r=0.22 ; \quad p<0.05) \quad$ and Scrotum Circumference have positive significant relationship with Skin Thickness $(r=0.07 ; p<0.05)$, Rump fat $(r=0.14$; $p<0.05)$, Rib fat $(r=0.21 ; p<0.05)$, and EMA $(r=0.24$; $p<0.05)$.

Performance testing of bullocks in central performance test is a model used in many countries in order to compare different bullock herds from different farmers in controlled environmental condition to identify significant effects influencing the growth of tested bullocks [48]. Performance testing it assist in predict future progeny and to provide the industry with objective performance information on individual animals in order to improve the biological and economic efficiency of beef production. The significant difference was observed during the start of Adaptation in Central Performance Test Phase C for large frame (LIM and SIM) breeds and medium frame breed (SGT). However, LIM 
and SIM showed significant high weight to start adaptation than SGT. According to [49], bullocks that are brought to Central performance test Phase $\mathrm{C}$ have just been weaned from their Dams and this quantifies that LIM and SIM had high (P $<0.05)$ weaning weight compared to the SGT. However, this is within the findings of [54] large frame shows significant high weight at the start of adaptation and it's an indication of high weaning weight compared to medium framed breeds ( $\mathrm{P}$ $<0.05)$ initial live weight. [50] indicates that weight at start of test has been shown to influence growth rate on test and this concludes performance of an animal during adaptation is determined by two factors namely: heredity and location. However, location usually refers to physical factors such as weather, landscape, diet, and it can include any non-genetic influences on performance such as management and economics [51].

The findings of adaptability are in line with [52], who indicated that adapting feedlot cattle with incremental increases in dietary concentrate from approximately 55 to 90 $\%$ of diet dry matter in less than approximately $14 \mathrm{~d}$, while allowing ad libitum access to feed, generally results in reduced performance during adaptation or over the entire feeding period [39]

According to [53], genetic correlation between each of two performance traits and its corresponding progeny test traits was high in spite of the difference in feeding regime. The genetic correlation coefficient and standard error for performance test final weight and progeny test 15 months live weight was $0.90 \pm 0.08$.

However, this justify the findings by [54], findings on animals that were perform tested in EFSVC, large frame breeds end the test with high weight $(326 \mathrm{~kg} \pm 8.8)$ compared to small framed breeds $(277 \mathrm{~kg} \pm 4.7)$. Reproductive behaviour is commonly affected by socialization and dominance. This relationship is driven primarily by age and body weight [55]. Furthermore, [56] examined the relationship of growth traits (e.g., average daily gain) with body measurements such as body weight, length, and height at the withers. There is significance difference between three breeds on body measurements $\mathrm{S} / \mathrm{HH}, \mathrm{BL}, \mathrm{SC}(\mathrm{P}<0.05)$ in Central Performance

However, the difference in breed size is in line with the findings of high-energy diet accelerated testicular development in the younger bulls, which is in agreement with the findings [55] that energy levels in diets significantly influence testicular development in yearling bulls. [43] demonstrated that regardless of the age or breed, the probability of a bull being a satisfactory breeder increased as $\mathrm{SC}$ increased, there is no significant difference within the breed ( $\mathrm{P}>0.05$ ). Moreover, $\mathrm{SC}$ is significant correlated to S/HH, BL, RUF, RIF and EMA in LIM. However, it was found that body measurements, in the absence of performance data might be helpful in identifying bulls that have a potential for high average daily gain.

TABLE IV: OVERALl CORRELATION: THE BODY MEASUREMENTS AND RTU OVERALL CORRELATION SCANS OF LIMM, SGT AND SIMM BEEF BULLOCKS BREED DURING PHASE C FROM 2007-2017

\begin{tabular}{|c|c|c|c|c|c|c|c|c|c|c|c|c|c|}
\hline $\begin{array}{c}\text { Body } \\
\text { M }\end{array}$ & AS & AEW & TED & AW & AADG & TWG & TADG & $\mathrm{S} / \mathrm{HH}$ & BL & $\mathrm{SC}$ & ST & $\mathrm{RF}$ & EMA \\
\hline AEW & $0.88^{* * * *}$ & & & & & & & & & & & & \\
\hline TED & $0.77 * * *$ & $0.82 * * *$ & & & & & & & & & & & \\
\hline AW & $-0.05^{\mathrm{NS}}$ & $0.43^{* * * *}$ & $0.27 * * *$ & & & & & & & & & & \\
\hline AADG & $-0.05^{\mathrm{NS}}$ & $0.43^{* * * *}$ & $0.27 * * *$ & $1.00 * * *$ & & & & & & & & & \\
\hline TWG & $0.16^{* * *}$ & $0.09 * * *$ & $0.64 * * *$ & $-0.11 * * *$ & $-0.11 * * *$ & & & & & & & & \\
\hline TADG & $0.16^{* * *} *$ & $0.09 * * *$ & $0.64 * * *$ & $-0.09 * * *$ & $-0.11 * * *$ & $1.00 * * *$ & & & & & & & \\
\hline S/HH & $0.35^{* * *} *$ & $0.36^{* * *} *$ & $0.42 * * *$ & $0.09 * * *$ & $0.09 * * *$ & $0.25 * * *$ & $0.25 * * *$ & & & & & & \\
\hline BL & $0.38 * * *$ & $0.37 * * *$ & $0.48^{* * *} *$ & $0.08 * * *$ & $0.08 * * *$ & $0.34 * * *$ & $0.34 * * *$ & $0.66^{* * *}$ & & & & & \\
\hline $\mathrm{SC}$ & $0.43^{* * *} *$ & $0.42 * * *$ & $0.52 * * *$ & $0.07 * * *$ & $0.07 * * *$ & $0.34 * * *$ & $0.34 * * *$ & $0.22 * * *$ & $0.30^{* * * *}$ & & & & \\
\hline ST & $-0.01^{\mathrm{NS}}$ & $0.07 * * *$ & $0.03^{\mathrm{NS}}$ & $0.18^{* * *} *$ & $0.18 * * *$ & $-0.05 * * *$ & $-0.05 * * *$ & $0.08 * * *$ & $-0.06^{\mathrm{NS}}$ & $0.07 * * *$ & & & \\
\hline RF & $0.05^{\mathrm{NS}}$ & $0.03^{\mathrm{NS}}$ & $0.16^{* * *}$ & $-0.03 * * *$ & $-0.03^{\mathrm{NS}}$ & $0.24 * * *$ & $0.24 * * *$ & $0.14 * * *$ & $0.09 * * *$ & $0.14 * * *$ & $0.15^{* * *} *$ & & \\
\hline $\mathrm{RF}$ & $0.09 * *$ & $0.09 * * *$ & $0.19^{* * *}$ & $0.02 * * *$ & $0.02^{\mathrm{NS}}$ & $0.39 * * *$ & $0.39 * * *$ & $0.11^{* * *}$ & $0.12^{* * *} *$ & $0.21 * * *$ & $0.20 * * *$ & $0.74 * * *$ & \\
\hline EMA & $0.45^{* * *}$ & $0.43^{* * *}$ & $0.47 * * *$ & $0.05^{* * *}$ & $0.05^{\mathrm{NS}}$ & $0.25^{* * * *}$ & $0.25^{* * *}$ & $0.29 * * *$ & $0.29 * * *$ & $0.24 * * *$ & $0.07 * * *$ & $0.04 \mathrm{NS}$ & \\
\hline IMF & $\stackrel{-}{-}^{-} 8^{* * *}$ & $-0.07^{\mathrm{NS}}$ & $0.12^{-} * * *$ & $0.20 * * *$ & $0.20 * * *$ & $-0.12 * * *$ & $-0.01^{\mathrm{NS}}$ & $-0.01^{\mathrm{NS}}$ & $0.117^{-} * * *$ & ${ }^{-}$ & $0.08 * * *$ & $0.03 \mathrm{NS}$ & ${ }^{-}-16^{* * *}$ \\
\hline
\end{tabular}

AEW=Adaptation End Weight, TED=Test End Weight, AW=Adaptation Weight, AADG=Adaptation Average daily Gain, TWG=Test Weight Gain, TADG=Test Average Daily Gain, S/HH=Shoulder/ Hip Height, BL= Body Length, SC= Scrotal Circumference, ST=Skin Thickness, RF=Ramp Fat, RF=Rib Fat, EMA= Eye Muscle, IMF= Intra Muscular fat.

\section{CONCLUSIONS}

Results obtained from this study indicated that temperate to high total heritability estimates for body measurements and bullock weight traits can be used effectively as guides to selection in improvement of different breed programmes. The study also revealed that a substantial variability among individuals breeds and for different breed population.

The Santa Gertrusi breeds adapted well comparing to other breeds based on its medium frame breed and its feed conversion ratio at 5.72 and gained about $1.67 \mathrm{~kg} / \mathrm{d}$. Limousin and Simmentaler breeds proved to consume more feed and gained lesser on daily gain. The Limousin started at $271.67 \mathrm{~kg}$, Simmentaler at $267.58 \mathrm{~kg}$ and Santa Gertrudis at $248.41 \mathrm{~kg}$, however the Limouson end weight decreased and to $448.50 \mathrm{~kg}$, with Simmentaler ending at 456.40 and Santa
Gertrudis. Therefore, the best breed adaptable was Limousin at $36.37 \mathrm{~kg}$ followed Santa Gertrudis at $29.78 \mathrm{~kg}$ and Simmentaler at $26.46 \mathrm{~kg}$. The SIM proved to have highest final weight gain, shoulder/hip height, body length, skin thickness and scrotum circumference, in comparison to the other two breeds. Whereas the Santa Gertrudis recorded higher values on the rump fat and Rib fat at $55.98 \mathrm{~kg}, 32.54$ $\mathrm{kg}$ respectively. The Eye Muscle and Intra Muscular Fat rated higher for Limousin to other two breeds.

The finding from the study indicates factors which guides animal producers on informed decision making to provide sound recommendations for possible improvements on breeding sound evaluation, selection, and production characteristics. This will allow analysis of data on different breeds and comparison of their performance with other breeds as well as within the same breed between different 
breeders. More emphasis on reproduction should be considered, to improve on the current situation where reproductive performance of bullocks is only judged based on scrotal circumference.

Results obtained from this study indicated that temperate to high total heritability estimates for body measurements and bullock weight traits can be used effectively as guides to selection in improvement of different breed programmes. The study also revealed that a substantial variability among individuals breeds and for different breed population.

The Santa Gertrusi breeds adapted well comparing to other breeds based on its medium frame breed and its feed conversion ratio at 5.72 and gained about $1.67 \mathrm{~kg} / \mathrm{d}$. Limousin and Simmentaler breeds proved to consume more feed and gained lesser on daily gain. The Limousin started at $271.67 \mathrm{~kg}$, Simmentaler at $267.58 \mathrm{~kg}$ and Santa Gertrudis at $248.41 \mathrm{~kg}$, however the Limouson end weight decreased and to $448.50 \mathrm{~kg}$, with Simmentaler ending at 456.40 and Santa Gertrudis. Therefore, the best breed adaptable was Limousin at $36.37 \mathrm{~kg}$ followed Santa Gertrudis at $29.78 \mathrm{~kg}$ and Simmentaler at $26.46 \mathrm{~kg}$. The SIM proved to have highest final weight gain, shoulder/hip height, body length, skin thickness and scrotum circumference, in comparison to the other two breeds. Whereas the Santa Gertrudis recorded higher values on the rump fat and Rib fat at $55.98 \mathrm{~kg}$, $32.54 \mathrm{~kg}$, respectively. The Eye Muscle and Intra Muscular Fat rated higher for Limousin to other two breeds.

The finding from the study indicates factors which guides animal producers on informed decision making to provide sound recommendations for possible improvements on breeding sound evaluation, selection, and production characteristics. This will allow analysis of data on different breeds and comparison of their performance with other breeds as well as within the same breed between different breeders. More emphasis on reproduction should be considered, to improve on the current situation where reproductive performance of bullocks is only judged based on scrotal circumference.

\section{ACKNOWLEDGMENT}

The authors acknowledge the following: The Agricultural Research Council for data collection, provision, skilled technical assistance and funding, Tshwane University of Technology for technical assistance and the Department of Agriculture Forests and Fisheries and Dr TJ Mpofu for statistical assistance.

\section{REFERENCES}

[1] Wiltbank JN, "Maintenance of a high level of reproductive performance in the beef cow herd," Vet Clin North Am Food Anim Pract, vol. 5, pp. 41-49, 1983.

[2] J. P. Kastelic, "Male involvement in fertility and factors affecting semen quality in bulls," Animal Frontiers, vol. 3, no. 4, Oct. 2013, doi: 10.2527/af.2013-0029.

[3] J. S. Crichton, A. W. Lishman, and S. F. Lesch, "Failure to Demonstrate a Relationship Between beef bull libido and conception rate," Journal of Animal Science, vol. 17, no. 1, pp. 27-30, 1987.

[4] D. P. Berry and S. C. Ring, "Short communication: Animal-level factors associated with whether a dairy female is mated to a dairy or beef bull," Journal of Dairy Science, vol. 103, no. 9, Sep. 2020, doi: 10.3168/jds.2020-18179.
[5] G. Gebreyesus, M. S. Lund, K. Kupisiewicz, and G. Su, "Genetic parameters of semen quality traits and genetic correlations with service sire nonreturn rate in Nordic Holstein bulls," Journal of Dairy Science, vol. 104, no. 9, Sep. 2021, doi: 10.3168/jds.2021-20403.

[6] Flowers WL, "Sperm characteristics that limit success of fertilization," Lournal of Animal Science, vol. 91, pp. 3022-3029, 2013.

[7] Carroll EJ, Ball L, and Scott JA, "Breeding soundness in bulls - a summary of 10940 examinations," J Am Vet Med Assoc, vol. 142, pp. 1105-1111, 1963.

[8] J. H. Alexander, "Bull breeding soundness evaluation: A practitioner's perspective," Theriogenology, vol. 70, no. 3, Aug. 2008, doi: 10.1016/j.theriogenology.2008.05.030.

[9] B. M. Alexander, "Reproductive performance of rams that failed breeding soundness evaluation: The need to reconsider the evaluation," Research in Veterinary Science, vol. 140, Nov. 2021, doi: 10.1016/j.rvsc.2021.09.005.

[10] Larso JL and Miller DJ, "Can relative spermatozoal galactosy transferase activity be predictive of dairy bull fertility?," Journal of Dairy Science, vol. 83, pp. 2473-2479, 2000.

[11] Williams WW and Savage A, "Methods of determining the reproductive health and fertility of bulls.," Cornell Vet, vol. 17, pp. 374-385, 1927.

[12] G. Fordyce, K. Entwistle, S. Norman, V. Perry, B. Gardiner, and P. Fordyce, "Standardising bull breeding soundness evaluations and reporting in Australia," Theriogenology, vol. 66, no. 5, Sep. 2006, doi: 10.1016/j.theriogenology.2006.03.009.

[13] K. Whitesell, D. Stefanovski, S. McDonnell, and R. Turner, "Evaluation of the effect of laboratory methods on semen analysis and breeding soundness examination (BSE) classification in stallions," Theriogenology, vol. 142, Jan. 2020, doi: 10.1016/j.theriogenology.2019.09.035.

[14] Barth AD, Bull Breeding Soundness, Third. Canada: Diplomate of the American College of Theriogenologists, 2013.

[15] P. J. Chenoweth and F. J. McPherson, "Bull breeding soundness, semen evaluation and cattle productivity," Animal Reproduction Science, vol. 169, Jun. 2016, doi: 10.1016/j.anireprosci.2016.03.001.

[16] Elmore R, Bierschwal CJ, Martin CE, and Youngquist RS., "A summary of 1127 breeding soundness examinations in beef bulls.," Theriogenology, vol. 3, pp. 209-218, 1975.

[17] OABS Development (PTY) LTD, "A Study on the potential product development for the commercialization and value add to beef products," Paarl, 2018.

[18] Barth AD and Walder CL, "Factors affecting breeding soundness classification of beef bulls examined at the Western College of Veterinary Medicine," The Canadian Veterinary Journal, vol. 43, no. 4, pp. 274-284, Apr. 2002.

[19] P. J. Chenoweth, "Sexual Behavior of the Bull: A Review," Journal of Dairy Science, vol. 66, no. 1, Jan. 1983, doi: 10.3168/jds.S00220302(83)81770-6.

[20] J. Felton-Taylor et al., "Effect of breed, age, season and region on sperm morphology in 11,387 bulls submitted to breeding soundness evaluation in Australia," Theriogenology, vol. 142, Jan. 2020, doi: 10.1016/j.theriogenology.2019.09.001.

[21] R. O. Pinho et al., "Lack of relationship between testicular echotexture and breeding soundness evaluation in adult Nelore bulls," Livestock Science, vol. 154, no. 1-3, Jun. 2013, doi: 10.1016/j.livsci.2013.03.001.

[22] M. Tomlinson, A. Jennings, A. Macrae, and I. Truyers, "The value of trans-scrotal ultrasonography at bull breeding soundness evaluation (BBSE): The relationship between testicular parenchymal pixel intensity and semen quality," Theriogenology, vol. 89, Feb. 2017, doi: 10.1016/j.theriogenology.2016.10.020.

[23] M. Martinez-Castillero et al., "Genetic parameters for fertility traits assessed in herds divergent in milk energy output in Holstein-Friesian, Brown Swiss, and Simmental cattle," Journal of Dairy Science, vol. 103, no. 12, Dec. 2020, doi: 10.3168/jds.2020-18934.

[24] V. S. Moncur, L. C. Hardie, and C. D. Dechow, "Genetic analysis of daily milk yield variability in Holstein dairy cattle in an experimental herd," Livestock Science, vol. 244, Feb. 2021, doi: 10.1016/j.livsci.2021.104397.

[25] B. A. Scott, M. Haile-Mariam, B. G. Cocks, and J. E. Pryce, "How genomic selection has increased rates of genetic gain and inbreeding in the Australian national herd, genomic information nucleus, and bulls," Journal of Dairy Science, vol. 104, no. 11, Nov. 2021, doi: 10.3168/jds.2021-20326.

[26] T. M. Englishby, K. L. Moore, D. P. Berry, M. P. Coffey, and G. Banos, "Herd-specific random regression carcass profiles for beef cattle after adjustment for animal genetic merit," Meat Science, vol. 129, Jul. 2017, doi: 10.1016/j.meatsci.2017.03.005. 
[27] Scholtz MM et al., "Livestock breeding for sustainability to mitigate global warming, with the emphasis on developing countries," South African Journal of Animal Science, vol. 43, no. 3, 2013.

[28] S. O. Borgen and B. Aarset, "Participatory Innovation: Lessons from breeding cooperatives," Agricultural Systems, vol. 145, Jun. 2016, doi: 10.1016/j.agsy.2016.03.002.

[29] E. R. I. Howarth et al., "Developing and validating attention bias tools for assessing trait and state affect in animals: A worked example with Macaca mulatta," Applied Animal Behaviour Science, vol. 234, Jan. 2021, doi: 10.1016/j.applanim.2020.105198.

[30] Kutz B, "Performance Testing Bulls on the Farm." 2006.

[31] Kunene NW and Fossey A, "A survey on livestock production in some traditional areas of northern kwazulu natal in South Africa," Livestock reproduction for rural development, 18-8, vol. 17, no. 1, 2006.

[32] F. and F. Department of Agriculture, "Department of Agriculture, Forestry and Fisheries. Annual report. Pretoria," Pretoria, 2014.

[33] Munyai FR, “An evaluation of socio-economic and biophysical aspects of small-scale livestock system based on a case study from Limpopo province," Bloemfontein, 2012.

[34] J. V. Yelich, "The Missing Piece of the Fertility Equation? Scrotal circumference effect on female fertility - is it real." UF/IFAS Department of Animal Sciences, University of Florida, Gainesville, FL, 2015.

[35] M. R. Silva, Pedrosa V. B, Borges-Silva J. C, Eler J. P, Guimarães J. D, and Albuquerque L. G, "Genetic parameters for scrotal circumference, breeding soundness examination and sperm defects in young Nellore bulls," Journal of Animal sciences, vol. 91, pp. 46114616, 2013.

[36] G. Mukuahima, "The performance of beef cattle bulls in the Vrede district of Mpumalanga, South Africa," Pretoria, 2004.

[37] E. S. E. Hafez, Principles of animal adaptation. In: Adaptation of Domestic Animals. Philadelphia: Ed. Hafez, E. S. E. Lea and Fabiger, 1968.

[38] M. K. Yousef, Principles of bioclimatology and adaptation. In: World animal science. B5. Bioclimatology and adaptation of livestock. Disciplinary approach. E, Johnson, H.D. The Netherlands, 1987.

[39] G. Leroy, P. Boettcher, B. Besbes, C. R. Peña, F. Jaffrezic, and R. Baumung, "Food securers or invasive aliens? Trends and consequences of non-native livestock introgression in developing countries," Global Food Security, vol. 26, Sep. 2020, doi: 10.1016/j.gfs.2020.100420.

[40] A. Valero, "Mating Interference Due to Introduction of Exotic Species," in Encyclopedia of Animal Behavior, Elsevier, 2019. doi: 10.1016/B978-0-12-809633-8.20855-8.

[41] P. E. Strydom, "Do indigenous Southern African cattle breeds have the right genetics for commercial production of quality meat?," Meat Science, vol. 80, no. 1, Sep. 2008, doi: 10.1016/j.meatsci.2008.04.017.

[42] I. Kohler-Rollefson, "Farm Animal Genetic Resources. Safeguarding national assets for good security and trade. A summary of workshop on farm animal genetic resources held in the Southern African Development Community (SADC)," CTA. Eschborn, 2004.

[43] P. McDonald, R. A. Edwards, J. F. D. Greenhalgh, and C. A. Morgan, Animal Nutrition, 6th ed. Edinburg: Pearson Education Limited, 2002.

[44] S. M. Scheepers, C. H. Annandale, and E. C. Webb, "Relationship between production characteristics and breeding potential of 25-month old extensively managed Bonsmara bulls," South African Journal of Animal Science, vol. 40, no. 3, Nov. 2010, doi: 10.4314/sajas.v40i3.1.

[45] P. J. Chenoweth, "Evaluation of natural service bulls - The 'other' BSE," The Veterinary Journal, vol. 168, no. 3, Nov. 2004, doi: 10.1016/j.tvj1.2003.12.005.

[46] T. J. Parkinson, "Evaluation of fertility and infertility in natural service bulls," The Veterinary Journal, vol. 168, no. 3, Nov. 2004, doi: 10.1016/j.tvj1.2003.10.017.

[47] E. H. Hay and A. Roberts, "Genomic evaluation of genotype by prenatal nutritional environment interaction for maternal traits in a composite beef cattle breed," Livestock Science, vol. 229, Nov. 2019, doi: 10.1016/j.livsci.2019.09.022.

[48] W. F. CATES, "Observation on scrotal circumference and its relationship to classification of bulls," Nebraska, 1975.

[49] Barth AD, Cates WF, and Harland RJ, "The effect of amount of body fat and loss of fat on breeding soundness classification of bulls," Can Vet J, vol. 36, pp. 758-763, 1995.

[50] Gibson TA, Vogt DW, and Massey JW, "Associations of scrotal circumference with semen traits in young beef bulls," Theriogenology, vol. 24, pp. 217-225, 1985.

[51] Coulter GH and Kozub GC, "Testicular development, epididymal sperm reserves and seminal quality in two-year-old Hereford and Angus bulls: effects of two levels of dietary energy," J Anim Sci, vol. 59, pp. 432-440, 1984.
[52] Barth AD, "The sequential appearance of sperm abnormalities after scrotal insulation or dexamethasone treatment in bulls.," Can Vet J, vol. 36, pp. 93-102, 1994.

[53] L. Vostry, J. Pribyl, L. Majzlik, H. Krejcova, and Z. Vesela, "Genetic evaluation of growth for efficient Bulls at a performance - Testing Station," Journal of Agrobiology, vol. 25, pp. 57-60, 2008.

[54] M. J. Lillywhite and J. Simonsen, "Understanding Factors That Influence Breeders to Sell Bulls at Performance Tests," Journal of Agricultural and Applied Economics, vol. 40, no. 3, pp. 865-877, 2008.

[55] M. F. Liu and M. Makarechian, "Factors influencing growth performance of beef bulls in a test station," Journal of Animal Science, vol. 71, no. 5, May 1993, doi: 10.2527/1993.7151123x.

[56] Botsime BD, "Influence of agro-ecological region on selected anthropometrical measurements of Nguni cattle in South Africa," 2007.

[57] M. S. Brown, C. H. Ponce, and R. Pulikanti, "Adaptation of beef cattle to high-concentrate diets: Performance and ruminal metabolism1," Journal of Animal Science, vol. 84, no. suppl_13, Apr. 2006, doi: 10.2527/2006.8413_supplE25x.

[58] P. F. Arthur, G. Renand, and D. Krauss, "Genetic and phenotypic relationships among different measures of growth and feed efficiency in young Charolais bulls," Livestock Production Science, vol. 68, no. 2-3, Mar. 2001, doi: 10.1016/S0301-6226(00)00243-8.

[59] Groenewals AP, "Submitted in partial fulfilment of the requirements for the degree," Pretoria, 2017.

[60] T. J. Engelken, "The development of beef breeding bulls," Theriogenology, vol. 70, no. 3, Aug. 2008, doi: 10.1016/j.theriogenology.2008.05.038.

[61] J. E. Brown, C. J. Brown, and W. T. Butts, "Evaluating relationships among immature measures of size, shape and performance of beef bulls," J. Anim. Sci, vol. 36, pp. 1010-1020, 1973.

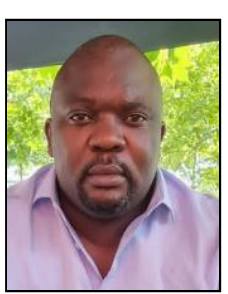

Mr Netshilema T. was born in Duthuni Village in Limpopo province of South Africa. He holds a Diploma in Agriculture in Animal Production receive in 2009, B. Tech in Agriculture Animal Production in 2013, M. Tech in Agriculture Animal Production 2021 at Tshwane University of Technology, Pretoria, South Africa.

Mr Netshilema Joined ARC in 2012 as research technician since 2015 . He worked as bull test manager at Glen office in the freestate region. His core skills are in animal agriculture research, animal research management \& leadership, policy development \& implementation, project design \& implementation. Other skills and experience are in coordinating multi-disciplinary, multi-cultural and international teams to implement research projects. He is an expert user of Continuous Improvement and Innovation methodology and integrates this approach ensure achievement of outcomes from research projects.

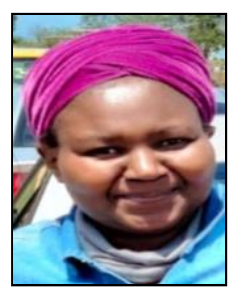

Zuma-Netshiukhwi G. was born in Balgown, KwaZulu-Natal province, South Africa.

$\mathrm{PhD}$ in Agrometeorology, University of the Free State 2012; Advanced Project Management Course, University of Leeds, 2021; Drought Risk Reduction in Water Resource Certificate, Cap-Net Virtual Campus 2016; Higher Diploma in Agricultural Research and Development with University of Wageningen in partnership with the Agricultural Research Counci (ARC), 2005; M.Sc. in Agrometeorology, University of the Free State, 2004; B.Sc. Agric. University of the Free State, 2001 in Bloemfontein.

She is currently a Researcher since 2014, specializing in the agrometeorology discipline working for Agricultural Research Council in Pretoria. She provided service as a Specialist in Agrometeorology: Applications South African Weather Services in 2013-2014. During the same period, she was an Assistant Lecturer at the University of the Free State. She served as a Junior Researcher at ARC from 2005 to 2012. In 2004 she served as a Training Mananger, for Dihwai Food and Agricultural Services.

She has contributed in following latest publications: Zuma-Netshiukhwi, Gugulethu, 2021. Weathering the Climate. Climate variability and changewhat is the difference? Harvest SA, January/February 2021, Issue 50. ZumaNetshiukhwi, Gugulethu, 2020. The importance of agrometeorological knowledge in agriculture. https://www.agriorbit.com/the-importance-ofagrometeorological-knowledge-in-agriculture. Zuma-Netshiukhwi, G and Mpandeli, S., 2019. The capabilities of Interdisciplinary Approach to Strengthening Farmers' Resilience to Climate Variability and Change. International Journal of Research in Agriculture and Forestry, Volume 6, 
Issue 6, pp 11-15. Zuma-Netshiukhwi, G., 2018. The Importance of Agrometeorological Services and Extension. Afgriland May/June Issue.

Zuma-Netshiukhwi, Gugulethu. 2017. Use of Operational Weather and Climate Information in Farmer Decision. Lambert Academic Publishing. Her research interests are agrometeorological matters, climate variability and change, indigenous knowledge systems on weather forecasting, climate predictions.

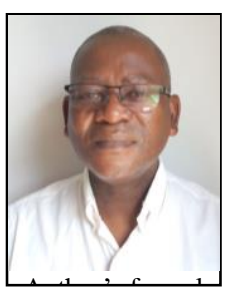

Dr Nkhanedzeni B. Nengovhela is a South African and currently holds a Scientist Manager: Animal Production position in the South African government Department of Agriculture, Land Reform \& Rural Development (DALRRD). Dr Nengovhela holds a BSc Agric \& Honours degrees from University of Limpopo based in Limpopo South Africa, MSc from Oklahoma State University, Stillwater, Oklahoma, USA \& PhD from University of Queensland, St Lucia, Queensland, Australia.

Dr Nengovhela worked for Limpopo \& North West Provincial Departments of Agriculture and Rural Development, University of Limpopo, Agriculture Research Services of United States Department of Agriculture and the Agriculture Research Council before joining DALRRD in 2017. He is currently serving in the board of the Wagyu Breed Society of South Africa. His core skills are in animal agriculture research, animal research management \& leadership, policy development \& implementation, project design \& implementation. Other skills and experience are in coordinating multi-disciplinary, multi-cultural and international teams to implement research projects. Currently leads assessment of livestock projects funded through government programmes and provate banks through blended funding. Leads an Australian \& South African bilateral project that involves several research institutions, provinces and universities. He is also involved in the review of new and old projects that are supported by industry and science funding institutions. He is an expert user of Continuous Improvement and Innovation methodology and integrates this approach ensure achievement of outcomes from research projects.

Dr Nengovhela completed a term in August 2021 of serving in the council of the South African Society of Animal Science (SASAS). He was the Editor of the Animal Husbandry \& Rural Development a developmental journal of SASAS until December 2015. He published peer reviewed articles, popular articles, conference proceedings and chapters in books. Gave keynote addresses, conference presentations, radio and a series of television lectures in his career. 